\title{
Tracing Communicative Patterns
}

\author{
A comparative ethnography across \\ platforms, media and contexts
}

\author{
Signe Sophus Lai, Jesper Pagh \& Fiona Huijie Zeng \\ Department of Media, Cognition and Communication, University of Copenhagen, Denmark, \\ signe.lai@hum.ku.dk,.jpagh@hum.ku.dk, fiona.zeng@hum.ku.dk
}

\begin{abstract}
This article outlines a research design for a qualitative comparative study of communication across platforms, media and contexts - in China, the US and Denmark. After addressing the limitations in previous research on digital media in everyday life, we argue in favour of a comparative ethnography of communication that emphasizes the study of intermediality by taking a people-centred approach. The methodological design combines network sampling and maximum variation sampling with communication diaries and elicitation interviews. This design makes it possible to collect small and deep communicative trace data, to capture individuals' unique linking of all the communication tools and channels available to them and, in turn, to identify the role of the internet as it interacts and intersects with other forms of communication.
\end{abstract}

Keywords: communicative patterns, comparative ethnography, diary, elicitation interviews, sampling strategies

\section{Introduction}

In July 2017, we set out to conduct qualitative fieldwork in China, the US and Denmark following a shared approach that allowed for comparative studies of communication practices across culturally distinct contexts. Here, we present that particular methodological set-up, which facilitates the mapping of complicated, ubiquitously embedded and mundane communication as it occurs in various everyday contexts. In other words, the article focuses on the small, even deep data that enable the analysis of a person's communication traces and the motives and incentives that trigger them. We pay particular attention to how communicative acts involving the internet interact and intersect with the total range of communicative practices of any individual. Applying an understanding of internet uses as communicative instances allows us to study connections and interdependencies between the myriad ways in which people can communicate and the ways in which people understand, differentiate, distinguish and choose, more or less

Lai, S. S., Pagh, J. \& Zeng, F. H. (2019). Tracing communicative patterns: A comparative ethnography across platforms, media and contexts. Nordicom Review, 40 (Special Issue 1): 141-157. doi:10.2478/nor-2019-0019. 
consciously, between those possibilities. The method provides researchers with a way to place digital trace data in the context of a person's total communicative repertoire by making it possible to discern how and why people move between digital and analogue communication. As such, the article offers a unique methodological design for comprehensively studying people's everyday internet use by capturing all communicative acts moving across different platforms, media and contexts.

Researchers focusing on digital communication often define their research area by the level of online or offline integration (Garcia et al., 2009) or delimit their scope by focusing on specific platforms for (online) communication (such as social media: Miller et al., 2016), specific media (such as smartphones: Thorhauge \& Lomborg, 2016) or specific contexts (such as the home: Bakardjieva, 2005). Although these limitation strategies define important areas for in-depth research, they also rule out the comprehensive study of connections and interdependencies between different platforms, media and contexts. Researchers studying social media cannot integrate this with knowledge about how and why people will move a conversation from a social media platform to a phone call. Researchers studying smartphones cannot integrate this with knowledge about how and why people use the same calendar software on their laptops as on their smartphones but in an entirely different manner. Researchers studying specific contexts like the home cannot integrate this with knowledge about how and why people use their tablets differently when they commute as opposed to when they are at home.

Taken together, the different strategies for limiting research scopes leave a gap in communication studies when it comes to analysing digital trace data in cross-platform (software), cross-media (digital/analogue hardware) and cross-context (physical/social situation) communication. To address this gap, we propose a qualitative methodological framework that, through the capture of small and deep data, enables mapping and analyses of the communicative practices that make up a person's daily communication. Rather than looking at a single platform, digital media in particular, or online and offline contexts in isolation, we "follow the people" (Marcus, 1995) and focus on the proliferation of ways in which people can communicate. Essentially, by focusing on people, we are able to follow in their footsteps. This allows us not only to look at their digital communicative traces but also to understand why they were left there in the first place and to analyse them as they relate to other forms of communication in which a person engages. As such, digital trace data are not studied in and of themselves but are contextualized and understood as part of a communicative environment in which people switch seamlessly between online and offline communication practices. In effect, the research design addresses the interwoven nature of people's online and offline presence (Simon \& Ess, 2015) and targets intermediality (Jensen, 2008) on the basis of the individual respondents and in close relation to their actual communication purposes, networks and situations, departing from the question: how do we study the situated enactment of communicative practices empirically within a comparative framework?

The participants for the study were recruited via a combination of network sampling (Heckathorn \& Cameron, 2017) and maximum variation sampling (Bryman, 2016). The approach combined recurrent interviews with 24-hour communication diaries in an iterative interview-diary-interview design. Interviews and diaries intersected by anchoring findings from one in the other. The diaries were time and context bound rather 
than reliant on memory, while the subsequent interviews contextualized the diary data points and allowed the respondents to infer meaning from, make sense of and co-interpret their communicative practices as they figured in their individual diaries. Unlike many other cross-national comparative studies that have focused on exploring differences, our research departed from the notion that, despite large cultural, political and economic differences between China, the US and Denmark (and indeed within them), communicative actions are driven by the same fundamental social mechanisms - such as a desire to maintain strong social ties (Granovetter, 1977). The shared methodological framework provided small and deep data that are comparable across contexts precisely because it focused on those fundamental incentives in a way that produced similar types of data. The comparisons, then, facilitated an analysis of the interactions between different cultural, political and economic contexts and the way in which those fundamental social mechanisms took shape.

The article is structured in three parts: first, a review of previous studies on the internet in everyday life; second, a discussion of different sampling strategies and qualitative data collection methods and an argument for the particular combination of network and maximum variation sampling with communication diaries and elicitation interviews; and, third, examples from our fieldwork that explain how the methodological design produced data that can comprehensively account for people's individual understandings of their communication practices across platforms, media and contexts.

\section{Studying the internet in everyday life}

The "ethnographic turn" in media studies heralded a shift in focus from the specific content of media to the everyday contexts in which media are used. The social uses of television (Lull, 1980) and Reading the romance (Radway, 1984) were among the studies that introduced this focus on contexts of use, which later re-emerged in studies of internet use in everyday contexts (Bakardjieva, 2005). In the first generation of internet studies, however, a specific understanding of the internet as a placeless cyberspace (Slater, 2002) resulted in studies targeting online contexts such as MMOs (Turkle, 1995), MUDs (Markham, 1998) and discussion forums (Baym, 2000) rather than the empirical contexts of use.

By the end of the millennium, scholars had begun challenging the notion of the internet as a cyberspace that could be examined and understood as a context in and of itself. Through extensive fieldwork in Trinidad, Miller and Slater (2000) demonstrated that the internet rather consisted of numerous technologies, used by different people in quite different real-world contexts, which were both shaped by and shaping the internet. Trinidadians were using the internet in one of three contexts: through a stationary computer at home, at work or in an internet café. With the development of mobile media, uses of the internet have diffused into a myriad of other daily life contexts. With uses of the internet entering into nearly all aspects of everyday life, communication researchers are, as we outlined earlier, resorting to various strategies to delimit the scope of their research objects. These strategies can be divided into four categories, as summarized below. 
Figure 1. Delimitation strategies: Four strategies for focusing research on the internet in everyday life

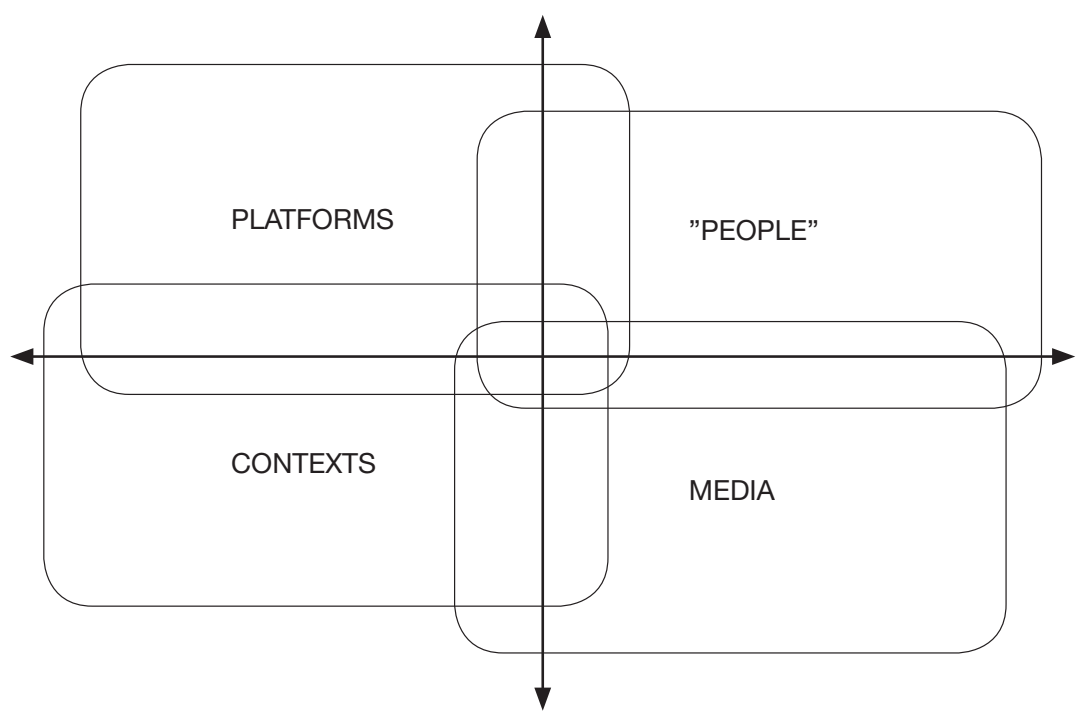

Comment: The figure indicates that the focus areas overlap, yet studies still delimit their object of study by adhering to one of the four strategies.

First, scholars have delimited their studies of the internet by focusing on specific contexts. In one strand of research, the domestication tradition, scholars have been increasingly attentive to the home as a particular empirical context wherein the social norms and physical surroundings of specific households govern the appropriation of different media, including the internet (Silverstone, 2006; Silverstone et al., 1994). In line with this tradition, Bakardjieva (2005) challenged the dichotomy between virtual and real lives. Looking at people's interactions in online communities, she developed a typology of five modalities of virtual togetherness, all of which are closely intertwined with people's offline realities.

Second, the overall research scope can be delimited by focusing on a specific medium, like mobile and smartphone use in everyday life (Ling \& Lai, 2016; Thorhauge \& Lomborg, 2016) or laptop computers (Anderson et al., 2009). Third, other researchers have focused on specific platforms of communication that originated online, like MySpace (boyd, 2006), SecondLife, World of Warcraft (Poels et al., 2015) and Twitter or Facebook (Marwick \& boyd, 2014; Miller et al., 2016).

Fourth, some scholars have taken individuals as the unit of analysis and followed their communication across platforms, media and contexts. Striving to obtain a holistic account of individuals' communication, uses of the internet are understood only as they relate to everyday life and to the entire assemblage of communicative practices that amounts to the individuals' communicative pattern. Applying this limitation strategy, Hasebrink and Domeyer (2012) mapped individuals' media repertoires, BeneitoMontagut's (2011) user-centred ethnography focused on interpersonal communication and Helles (2011) connected lifestyle types with different configurations of media and internet use. 
It is within this fourth strand of research strategy that we place our study. In effect, we examine communicative patterns, with or without the internet, through mundane actions across any platform, medium and everyday context. This requires an intense and comprehensive relation to the individual participants, which in turn constrains the number of research subjects. Hence, we learn a lot (deeper data) about a few (smaller samples).

To sum up, this study is placed in the tradition of everyday-life internet studies and strives to access people's communicative practices in a comprehensive manner while accounting for the increased complexity, mobility and fluidity in those practices. In the following part, we discuss the sampling strategies and qualitative data collection methods as they relate to the research design proposed in this article.

\section{Sampling maximum-variation networks}

Although the function of any sampling strategy is to lend validity to the study at hand (Morse \& Niehaus, 2016), researchers have often neglected to argue thoroughly, if at all, in publications for their choice of sampling strategy. Rather, sampling has been treated shallowly as a technical research state, without explaining the ways in which the qualities of the sampling strategy coincide with the aims of the study.

With the purpose of gaining in-depth knowledge of communicative practices and their relationships with culture, regulation, market and technological infrastructure across comparative research contexts, we rest our argument on Marcus's (1995) study, which noted the pitfalls in attempting to explain macro-structures through a single-case microperspective. To avoid this, Marcus called for an ethnography that is multi-sited so that each site is differentiated enough from the others to be able to give a unique perspective on the same macro-structures (be they for instance cultural, political or economic). In Marcus's framework, multi-sitedness is the result of following things, metaphors, stories, biographies, conflicts or, as is the case here, people across diverse sites. We propose to achieve this by sampling respondents through a combination of network sampling with maximum-variation sampling. This section outlines the values in the combination of these specific strategies.

\section{Network sampling}

Network sampling is a purposive, non-probability sampling strategy. As such, network sampling targets specific groups or types of people, and the sample will not be reflective of a wider population or enable statistical generalizations. Additionally, recent ethnographic research (Cook et al., 2009) has challenged the traditional notions of the ethnographic field site as a geographically bounded location and suggested network sampling as way for researchers to construct the field site by tracing the nodes of a social network (Burrell, 2009).

To bridge different social networks, researchers can network vertically through strong ties only or horizontally through both weak and strong ties (Granovetter, 1977). The latter essentially entails "casting the sampling and recruitment net wide rather than deep" (Geddes et al., 2017: 2); accordingly, the former has often been put forward as the ideal that correlates with an effort to make in-depth descriptions of a given phenomenon. Networking horizontally, however, can prevent sampling stasis and enable heterogeneity not 
only between networks but also, to some extent, within networks. In our study, we used both networking strategies depending on the specific network and the sampling situation.

Following Noy's (2008) concept of sampling knowledge, the method of sampling networks can generate important social knowledge of an interactional character in and of itself. The sampling then provides additional knowledge to that produced through interviews and diaries - for instance in the form of different perspectives on the same communicative relationship between two individuals in a network.

\section{Maximum variation sampling}

One way of constructing the spatial components of a networked field site is by applying a maximum variation principle to the sampling of the network(s). This method helps to locate cases that are heterogeneous regarding selected characteristics that are thought to have important influences on the object of study (Bryman, 2016; Morse \& Niehaus, 2016). As such, the term maximum variation refers to the variation between cases rather than to the variation of the full population of the field site(s). While being aware of the limitations that a small n-study puts on the ability to achieve maximum variation in a high number of variables, we sought to achieve the maximum achievable variance in seven variables when sampling our participants, namely 1) age, 2) gender, 3) place of residence and household, 4) ethnicity, 5) educational level, 6) religious beliefs and 7) relationship and parental status, to obtain the broadest possible representation of those factors. Applying maximum variation as a sampling strategy in a qualitative study can, firstly, provide deep descriptions of the individual cases and show the diversity between them and, secondly, highlight patterns that traverse variations and prove to be important precisely because they are unaffected by diversity (Patton, 2015). Figure 2 illustrates the different networks in our study.

\section{From going places to tracing relations}

Although Marcus, in his argument for a multi-sited ethnography, emphasized place as a physical location, our adaptation of his argument to the analysis of field sites as networks (Burrell, 2009) resituates place as being less dependent on physical properties and more dependent on relational properties. Maximum variation can therefore be seen as a tool to combine the deep description of usage patterns with the often shallow superimposition of macro-influences at the analytical level. That is not to say that maximum variation in itself meets the requirements of the kind of experimental ethnography for which Marcus called. It is rather to propose a sampling strategy that addresses those same issues: that a disorganized system (Lash \& Urry, 1987) cannot be represented adequately through homogeneous cases.

The combination of maximum variation and network sampling in our study generates what can be described as constructive interferences, whereby differences between the approaches can simultaneously provide a stronger understanding of communicative practices both in isolation and in relation to structural influences. While limiting the sampling to people who are connected through a social network potentially restricts maximum variation due to homogeneity within networks, we obtained heterogeneity across networks by finding inherently different starting nodes for the networks. In effect, each network acts as a distinct place, wherein people's relationships, and the ways 

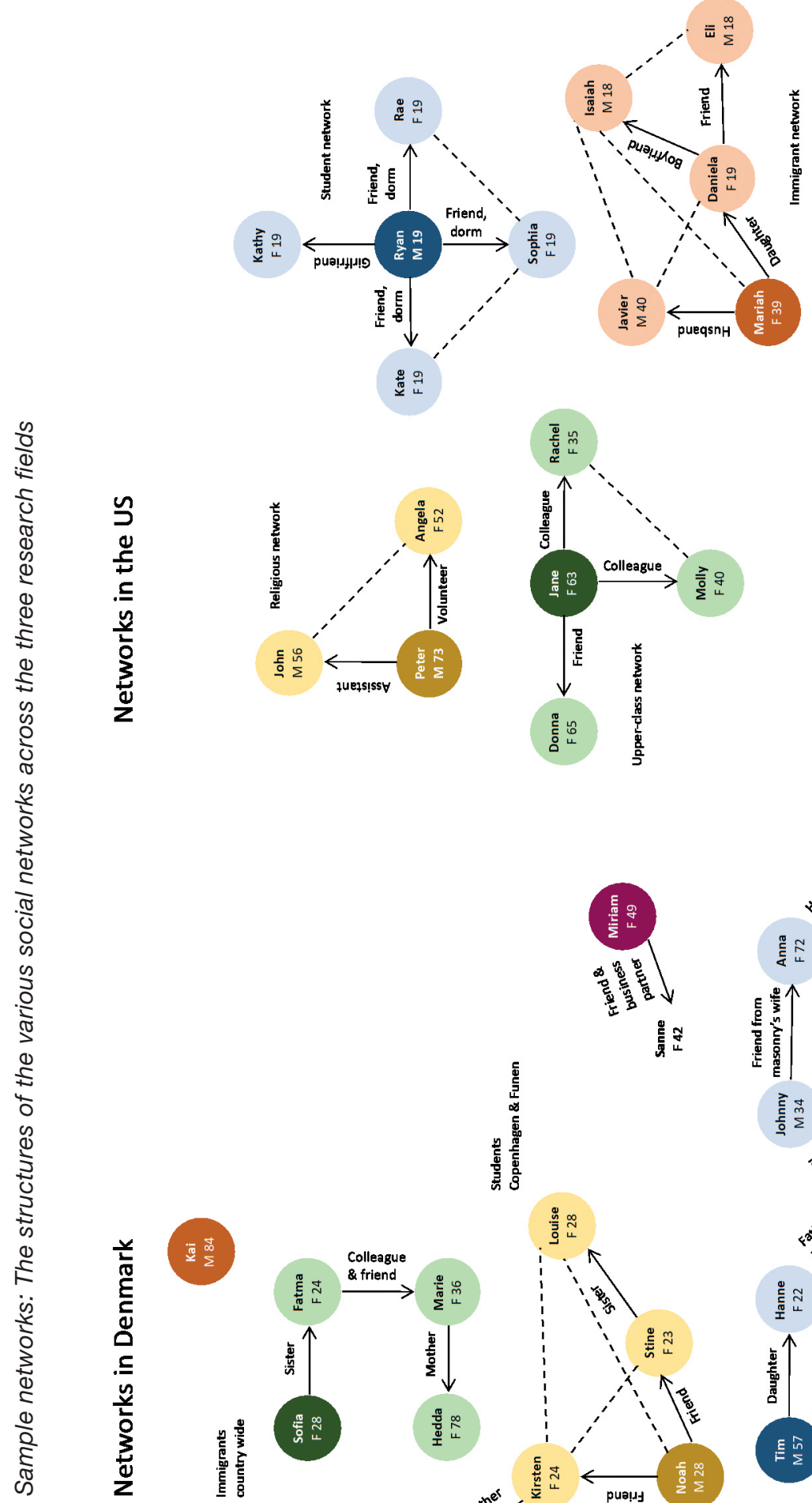

ง
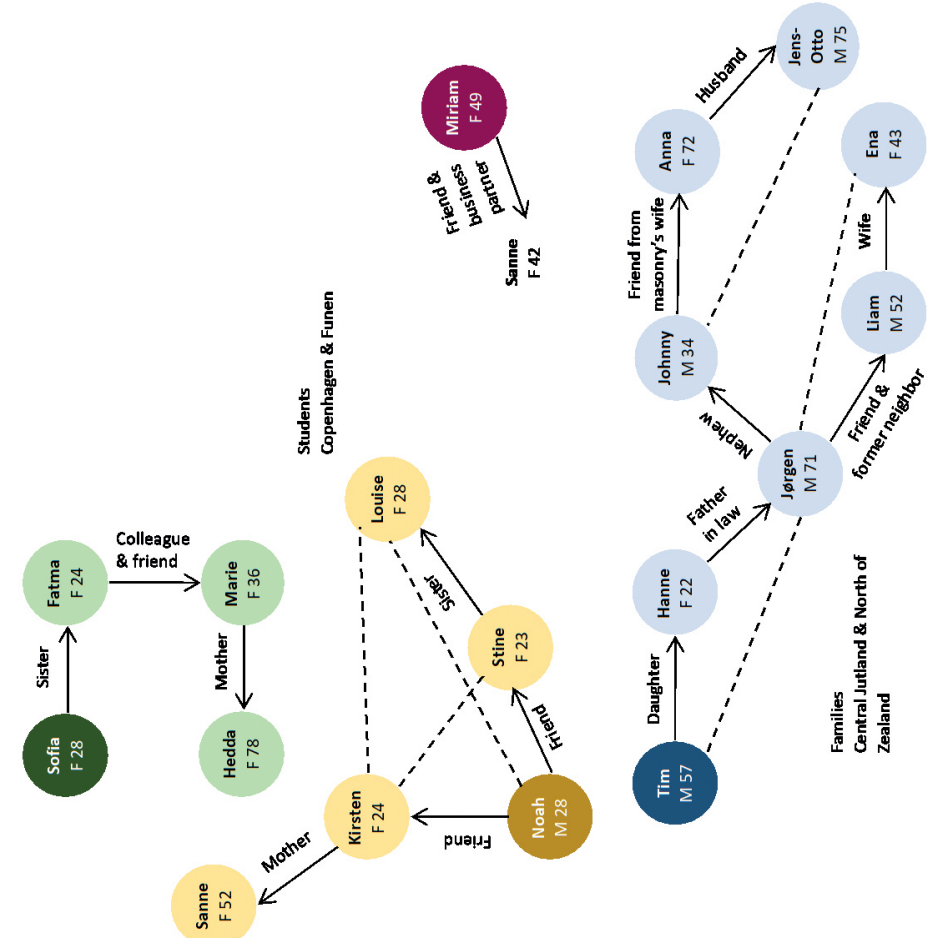

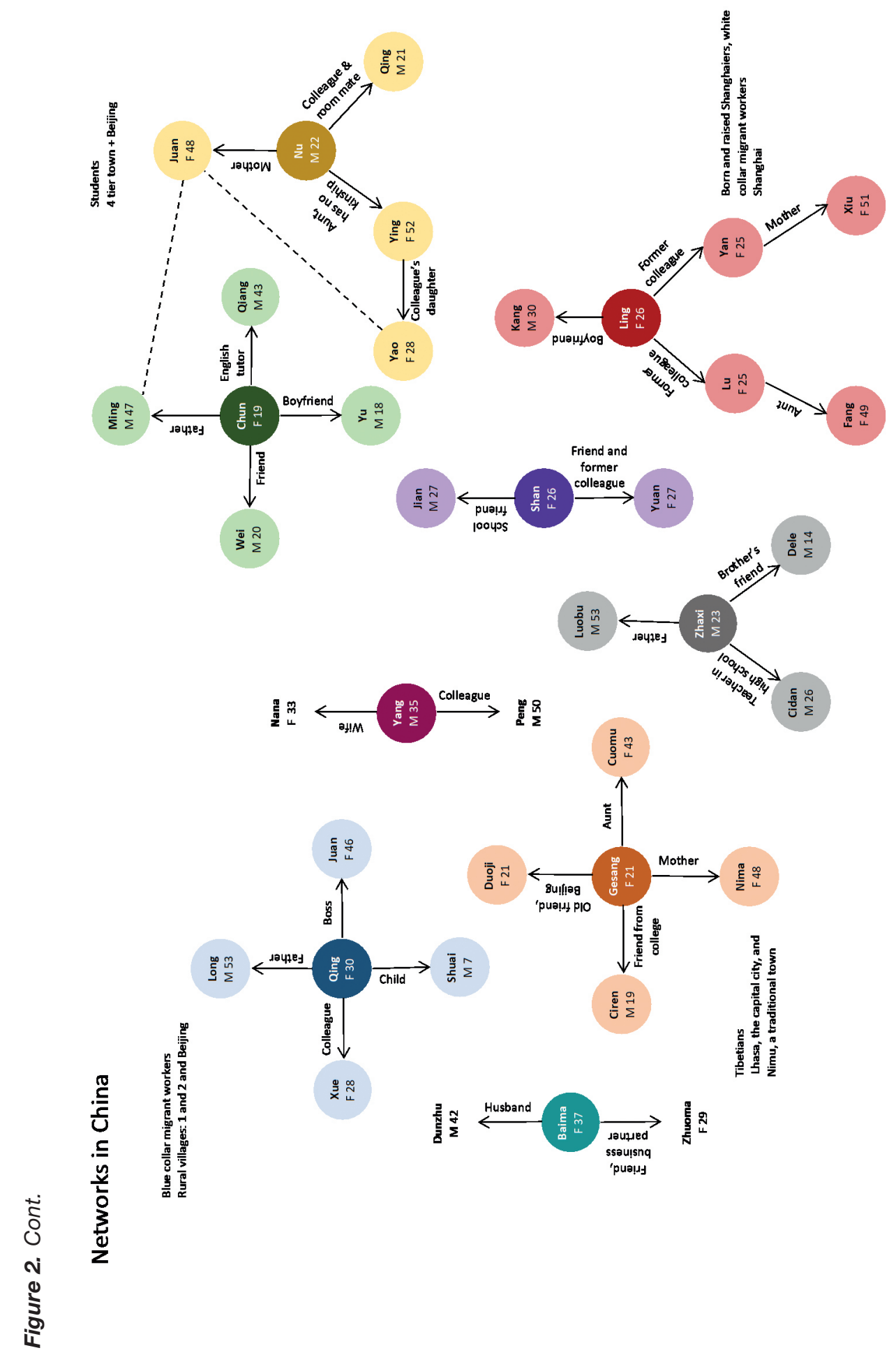
in which their communication influences these relationships (and vice versa), can be analysed. In the next part, we discuss the combination of communication diaries and elicitation interviews as an approach to following people in their communicative networks to collect the digital trace data left behind from their communicative moves across platforms, media and contexts.

\section{Diaries: Structured and unstructured approaches}

Diary studies have been an established approach in social science research since the 1920 s, with time use diaries in the 1960s and onwards being the most widely recognized form (Couldry et al., 2007). Critics have identified many limitations to time use diaries, particularly with regard to low response rates and participants' ability to estimate reliably the time spent on mundane activities. However, the advantages of the method are evident in that diary data are collected close to the time of the registered event (ibid.) and that self-produced diaries generate data on the everyday context of mundane practices that would be difficult to obtain otherwise (Zimmerman \& Wieder, 1977). Incorporating diaries into our design supports the research aim by providing a broad representation of participants' communicative practices while minimizing our interference with their daily lives.

Research diaries can be devised on a continuum ranging from fully structured to entirely unstructured, which is also a distinction between "objective" and "subjective" approaches. Whereas time use diaries belong to the more structured and "objective" approach, "subjective" unstructured diary studies emphasize not confining the reflection of the participants and making the researcher as unobtrusive as possible in the data collection process. For instance, in a highly structured diary study, Hargittai and Karr prompted their participants recurrently at random times, asking them: "Please reply with your location, current activity, people you are with (number, your relationship to them, gender) and any media you are using now" (2009: 20). In contrast, Markham and Couldry, using unstructured weekly diary entries, explained that "The priority was to access people's processes of reflecting on media use rather than cataloguing consumption habits" (2007: 688).

Couldry and colleagues (2007) described how research tends to favour either structured or unstructured approaches, with unstructured diaries being the most common component of ethnographic studies. The diary design that we argue for here, however, is innovative as it combines the two approaches into one: an objective approach with subjective measures. That is, while our diary method is quite structured in what to report and when, it is fully unstructured when it comes to how to report. Through this coupling, the type of data collected was manifold, although it reported on media use instances each time, and the diary was more organically incorporated into the existing communication practices of the participants. At the end of the introductory interview, the participants were given oral and written instructions on what to report in the communication diary, allowing questions to be answered in person. We asked them to register and report answers to the following questions whenever they used media (analogue or digital), throughout the day and temporally as close as possible to the actual uses, for one or two full days. 
1. When was it and for how long (if this is not implied)?

2. Where were you (if this is not implied) and who were you with (if anyone)?

3. What were you using the media for (for instance texting, social network sites, email, applications, TV or radio programmes, phone calls)?

4. Who were you communicating with (if anyone)?

These rather structured instructions enabled the data collection to stay close to the actual instance of media use as well as the potential trace data left in its wake, giving greater accuracy to the data reported. Therefore, we were able to infer communicative purposes of the media uses as they were happening and to ask clarifying questions then and there. They also allowed for the small, mundane acts of communication - such as the many times a person notices messages on the lock screen of a smartphone or the ritual text messages containing nothing but phatic conversations - to enter into the foreground. To provide further guidance regarding what to report, a definition of what we meant by media, which had been open to interpretation during the introductory interview, was given to the participants, so they all shared a similar idea of what media use entailed when reporting back to us.

For each report instance, the participants were then free to decide on the report platform and medium (e.g., social media, email, phone calls, tablets and paper records) and report type (e.g. texts, visuals, as well as audio and video messages). Additionally, they were introduced to automated data collection apps and software for different digital devices, and they could opt in and out of these. Hereby, the diary reporting was anchored in their existing media habits and contingent on their regular media uses, which minimized the effect of the reporting on the routines of the participants (Carter \& Mankoff, 2005). Hence, the specific amalgamation of structured registration with unstructured reporting allowed the researcher to stay close but also out of the way during the data collection. Moreover, the ways in which the participants reported to us in terms of report types, platforms and media provided valuable insights into their general communicative choices and patterns.

We recognize, however, that the diary method is not able to catch every instance of communication, which was also not the purpose. The data collection depends on the participants' ability to remember to register and report whenever they use a medium. Even though the diary was structured to enable the reporting of trivial and habitual media use, it was inevitable that some uses, to some of the participants, were so engrained in habit that they did not register the acts themselves. In other cases, the participants became too self-conscious and in effect changed their media habits. We argue, however, that the design of the diary registration and reporting process minimized our intrusion into participants' routines while maximizing the participant feedback. In addition, the combination of diaries and interviews allowed us to ask about media uses that had passed unregistered as well as about face-to-face communications throughout the diary day. Hence, we employ the concept of communication diaries, since the specific fusion of diaries and interviews captures both mediated and non-mediated communication. The diaries, then, represent a different type of trace data from that found in mining uncontextualized and non-consented Facebook comments, retweets or YouTube likes. The situated enactment of the participants' communicative practices amounts to different 
traces that they themselves decided to pass on to us (or not). As such, rather than being left out of the research process, the participants owned, reflected on and co-interpreted the traces of their communicative actions, thereby adding information on contexts of use, motives and purposes. In the following, we discuss the advantages and challenges of interchangeably augmenting diary data with interviews.

\section{Interviews: Introductory and elicitation}

In the interview-diary-interview structure of our study, the purpose of the introductory interview was to become acquainted with the participants, their everyday life and their media use in general, whereas the second interview was an elicitation interview taking prompts from both the diary and the introductory interview.

The methodological combination of diaries and interviews in social science can be traced back to the 1970s, when Zimmerman and Wieder (1977) proposed a diary-interview method to document participants' activities in a more feasible manner than through participation observation. Similarly, in recent media repertoire research, Hasebrink and Domeyer (2012) explored the diversity and differences between participants' media repertoires by documenting their media use through diaries and in follow-up interviews, generating detailed and descriptive data of participants' media use as well as facilitating further interpretations of those uses. In other words, the diary-interview approach enables researchers to employ diary data in two ways: first, as data themselves and, second, as prompts for the elicitation interview questions. The diaries in our study the ways in which participants chose to report, the platforms and media that they used, their frequency of reporting, the people with whom they communicated and the ways in which they reached out to us - provide important data on the communicative practices of those respondents. The follow-up interviews allowed for participant reflections and a line of questioning that can be rooted in the actual communications of each participant.

In the introductory interview, we became acquainted with the participants (asking them about their daily routines, their close network, the things that are important to them and the media that they use). We asked for "tours" of their smartphones, tablets and computers, posing questions concerning notifications and sound settings, particular apps and the general organizing principles of their devices (app locations, folders and pinned apps).

Elicitation interviews have commonly been described as interviews in which another data source is used to elicit or spark a conversation within a mixed-method framework (Gundelach et al., 2014). Examples of different constellations of interviews and elicitation data include observational studies (Beneito-Montagut, 2011), screenshots and GPS data points (Thorhauge \& Lomborg, 2016), open-ended reflexive diaries (Markham \& Couldry, 2007) and log data (Anderson et al., 2009).

Although we had a preliminary interview guide for the elicitation interview, it was comprehensively rewritten to combine discussion topics with concrete prompts from the introductory interview as well as the diary. The tailored line of questioning made it easier for the participants to relate to each topic and encouraged them to fill in the gaps in the diaries and to co-interpret their data. As such, the diary data allowed us to ask more abstract questions, as the questions were tied to the participants' own concrete acts of communication. It also brought attention to otherwise ubiquitous and indiscernible 
communication instances, allowing the participants to elaborate on the circumstances and contexts of those specific instances. Finally, by asking questions concerning the blank spaces and periods of non-media use in the diaries, we targeted the communication that was not present in the diary entries, namely face-to-face interaction. As part of a comprehensive study of the role of the internet in everyday communication, faceto-face interactions play a significant role in the multitude of ways in which people can communicate.

Having outlined the sampling strategies and empirical methods, the last part of the article elaborates on our design by providing data examples that show how the combination of communication diaries and interviews enabled us to follow people and analyse their communicative patterns.

\section{Following people}

We have argued that, unlike research that delimits its scope to specific platforms, media or contexts, our research design enables us to follow communication flows wherever they go: when participants suddenly switch between the affordances (Hutchby, 2001) of different platforms and media, when they communicate in several contexts at once or when they find themselves in private contexts in which researchers cannot usually follow them. We now present data examples from three participants, who are maximally different from each other, as they move across platforms, media and contexts. The examples show how we empirically approached the situated enactment of the participants' communication patterns insofar as they could be traced in the diaries as well as in the subsequent conversations with them. Ena, in Denmark, a 46-year-old first-generation immigrant from Eastern Europe, works as a part-time nursery teacher and lives with her husband and children; John, from the US, is a 56-year-old painter of Catholic icons who lives alone in Chicago and works part time as a church janitor; and Chun, from China, is a 19-year-old college student who lives in Beijing and majors in Japanese studies.

\section{Cross-platform communication}

In any individual communication diary in our sample, several platforms are represented throughout the day, and we asked the participants to reflect on instances of digital crossplatform communication. In Denmark, Ena abruptly shifted from writing to her friend in Eastern Europe on Facebook Messenger to calling her over FaceTime. She described how she had called her friend because the conversation turned to a serious topic that she did not feel like talking about in text. Being able to hear her friend's voice, she managed to console her and felt more comfortable about being able to say the right things to her. In the US, John used different platforms to sustain his business of selling religious paintings. For instance, he would switch interchangeably throughout the day between replying to inquiries and checking incoming orders on his email and on his personal Facebook profile. He used to sell his paintings only through exhibitions and word of mouth, but friends encouraged him to employ the digital platforms as a way to enhance his business by reaching a wider range of possible buyers. In China, Chun explained that she had two online personalities on two different social media platforms. On the first one, WeChat, everyone knew her real identity and she only shared positive 
content within this network. On the second, Fanfou, she used an anonymized identity, and on this network she would pour out her negative thoughts without these postings being related to her real identity.

In the diaries, we could observe participants switching between different platforms, and, through the reflections and co-interpretations of the participants in the subsequent elicitation interviews, we were able to infer meaning from the stand-alone diary entries. It was only through these entries that it became possible to capture the mundane, minute and at times complex moves between platforms - as well as moves between media.

\section{Cross-media communication}

The communication diaries contained the different media that the participants own and switch between or use in parallel. In China, Chun reported on a situation in which she was watching and discussing a Japanese TV series on her laptop while having lunch with her roommate. In a case of parallel media use, Chun took a picture of the laptop screen with her phone and posted this to her WeChat network, commenting that she was missing out on the series' details because she was distracted by the lunch situation. In the US, one of John's tasks for the church involved assisting a 73-year-old deacon with his email exchanges. The deacon had a stationary computer that he did not know how to operate, so John would log into the deacon's system, check his emails and then print them for the deacon to read. Subsequently, the deacon would make hand-written replies that John could then type into the email program and send out on behalf of the deacon. As such, John functioned as an intermediary between the deacon and his network as well as between the deacon and the computer. In Denmark, Ena, filling in the diary on New Year's Eve, spent most of her time in the kitchen. She used her phone to look up recipes for the evening's dinner, only to switch to her tablet once she found a suitable recipe. The tablet, she explained, had a bigger screen and was more easily incorporated into the cooking situation in the kitchen.

Like cross-platform communication, the concrete acts of switching between different analogue or digital media served as a point of entry into the individuals' unique communication pattern. Being able to ask concrete rather than abstract questions regarding those media uses made it possible for the participants to express the elaborate systems of thought and behaviour grounding these exchanges. Using different media in sequence or in parallel was often not based on conscious choices. However, when asked, the participants were able to provide reasons that rested on the affordances of the media that they were using and of their current contexts.

\section{Cross-context communication}

The in-situ self-reporting format of our communication diaries allowed communication instances taking place in intimate contexts to be included in the study. In the US, John used his text messages from his phone to coordinate a meeting with his brother regarding an intimate family issue. Their mother had recently passed away and John and his brother were meeting to discuss how to take care of their 90-year-old father. Later that day, after hours of no diary updates, John explained that the two of them had a rule never to use media when they were together. In Denmark, Ena, who suffered from posttraumatic stress disorder after fleeing her home country during wartime many years ago, 
explained that she took her tablet to bed each night and put on white noise videos from YouTube to help her fall asleep. In China, Chun went on a romantic date with another participant in her network, Yu, and they both used their smartphones to take pictures of the food and store memories from the date.

What these contexts have in common is that they are highly intimate and the actual presence of another person, let alone a researcher, would have impinged on the situation and changed it altogether. The diaries, being our conceptualization of "being there", thus enabled contexts like these to be part of the elicitation interview and the study as a whole.

These three participants exemplify how the small and deep data collected encompass the cross-platform, cross-media and cross-context communications of an individual. Taken together, the communication instances mapped the full spectrum of communicative possibilities relating to the individual participants, and the interviews contextualized these practices by adding aspects of everyday life, personal values, attitudes and aspirations as well as participant interpretations. The data examples illustrate how the coherent methodological design was implemented in the three very distinctive national fields and lay the ground for future comparative analysis. Upcoming work will include a thorough analysis of cross-cultural comparisons. We also, however, acknowledge that approaching the field with the aim of capturing a person's entire communication repertoire carries with it certain limitations.

\section{Limitations of following people}

We identify at least four limitations of our research design. First, the methodological set-up is demanding in time and effort for both participants and researchers because of the recurrent and extensive contact throughout the research period. Second, due to the intensive research participation, we ended up with a comprehensive snapshot of the participants' communicative pattern that was susceptible to their current life circumstances and did not enable us to make any longitudinal inferences. Third, we lost depth when it came to any one individual platform, media or context while trying to follow connections across them. Fourth, as opposed to observational studies, in which the researcher is entirely in charge of the data collection, our data quality varied in that it depended heavily on the ability of our participants to report their communicative instances.

\section{Concluding remarks: Comparing communications}

This study was designed to enable comparisons of communicative patterns in each field and across national contexts. Within each field, the coupling of network and maximum variation sampling produced a number of inherently different networks of inherently different people whose communicative patterns can be comparatively analysed relative to their everyday lives. By applying the same combination of sampling strategies across the three fields, the diverse individual communicative patterns can also be comparatively analysed in relation to the cultural traditions, regulatory regimes, market structures and technological infrastructure pertaining to each field.

The article presented an answer to the methodological question of how to study empirically the situated enactment of communicative practices within a comparative 
framework. In this context, the question of how not to delimit the research area to specific platforms, media or contexts was also addressed with the introduction of the novel approach of following participants' cross-platform, cross-media and cross-context practices through their self-reports as well as their subsequent elaborations on these data traces. Any methodological selection is simultaneously a deselection, to which the above-mentioned limitations are also a testament. We do not argue that this approach is a way to capture everything; rather, it is an attempt to study communication comprehensively through the collection of small and deep data. The research design makes it possible to capture the intermediality of the basis of an individual's unique linking of all the communication tools and channels available to him or her and, in turn, a way to identify the role of digital communication tools as they interact and intersect with other forms of onlife communication. As such, the methods that we presented address how to study the internet in its increasingly ubiquitous presence in everyday life by mapping communication - online, offline or both at once - as it happens and wherever it happens. The approach is a novel iteration of mapping and analysing digital media use and digital trace data as part of a holistic view of individual communicative practices. It has been suggested time and again that online and offline experiences cannot be explained separately. We take this argument one step further and suggest that future research into digital communication needs to take the interwovenness seriously, not just between online and offline contexts but between communicative practices in general, as they are performed across platforms, media and contexts.

\section{Funding}

This study is part of the research project The Peoples' Internet, which is funded by the Carlsberg Foundation - Semper Ardens [CF16-0001].

\section{References}

Anderson, K., Nafus, D., Rattenbury, T. \& Aipperspach, R. (2009). Numbers have qualities too: Experiences with ethno-mining. Ethnographic Praxis in Industry Conference Proceedings, 1: 123-140. https://doi. org/10.1111/j.1559-8918.2009.tb00133.x

Bakardjieva, M. (2005). Internet society: The Internet in everyday life. London, UK: SAGE Publications Ltd. http://site.ebrary.com/lib/alltitles/docDetail.action?docID $=10218047$

Baym, N. K. (2000). Tune in, log on: Soaps, fandom, and online community. Thousand Oaks, CA: Sage Publications. Retrieved from http://site.ebrary.com/id/10582332

Beneito-Montagut, R. (2011). Ethnography goes online: Towards a user-centred methodology to research interpersonal communication on the Internet. Qualitative Research, 11(6): 716-735. doi: https://doi. org $/ 10.1177 / 1468794111413368$

boyd, D. (2006). Friends, friendsters, and top 8: Writing community into being on social network sites. First Monday, 11(12). http://firstmonday.org/ojs/index.php/fm/article/view/1418

Bryman, A. (2016). Social research methods (5th ed.). New York: Oxford University Press.

Burrell, J. (2009). The field site as a network: A strategy for locating ethnographic research. Field Methods, 21(2): 181-199. doi: https://doi.org/10.1177/1525822X08329699

Carter, S. \& Mankoff, J. (2005). When participants do the capturing: The role of media in diary studies. In Proceedings of the SIGCHI conference on human factors in computing systems, CHI '05 (pp. 899-908). New York, NY: ACM. doi: https://doi.org/10.1145/1054972.1055098

Cook, J., Laidlaw, J. \& Mair, J. (2009). What if there is no elephant? Towards a conception of an un-sited field. In M. A. Falzon (ed.), Multi-sited ethnography, theory, praxis and locality in contemporary social research. New York: Routledge.

Couldry, N., Livingstone, S. \& Markham, T. (2007). Media consumption and public engagement - Beyond the presumption of attention. London: Palgrave Macmillan UK. 
Garcia, A. C., Standlee, A. I., Bechkoff, J. \& Cui, Y. (2009). Ethnographic approaches to the Internet and computer-mediated communication. Journal of Contemporary Ethnography, 38(1): 52-84. doi: https:// doi.org/10.1177/0891241607310839

Geddes, A., Parker, C. \& Scott, S. (2017). When the snowball fails to roll and the use of "horizontal" networking in qualitative social research. International Journal of Social Research Methodology, 0(0): 1-12. doi: https://doi.org/10.1080/13645579.2017.1406219

Granovetter, M. S. (1973). The Strength of Weak Ties. American Journal of Sociology, 78 (6): 1360-1380.

Gundelach, P., Nielsen, R. S. \& Frederiksen, M. (2014). Mixed methods-forskning, principper og praksis. 1. udgave. Samfundsvidenskabernes metoder $<<$ bind 4=4>>. Copenhagen: Hans Reitzel.

Hargittai, E. \& Karr, C. (2009). WAT R U DOIN? Studying the thumb generation using text messaging. In E. Hargittai (ed.), Methods from the trenches. Michigan: The University of Michigan Press. Retrieved from http://www.kriso.ee/methods-from-trenches-db-9780472070268.html

Hasebrink, U. \& Domeyer, H. (2012). Media repertoires as patterns of behaviour and as meaningful practices: A multimethod approach to media use in converging media environments. Participations: Journal of Audience and Reception Studies, 9(2): 757-779.

Heckathorn, D. D. \& Cameron, C. J. (2017). Network sampling: From snowball and multiplicity to respondentdriven sampling. Annual Review of Sociology, 43(1): 101-119. doi: https://doi.org/10.1146/annurevsoc-060116-053556

Helles, R. (2011). Hverdagslivets nye medier. Dansk Sociologi, 21(3): 49-63.

Hutchby, I. (2001). Conversation and technology, from the telephone to the Internet. Cambridge \& Malden. Polity Press.

Jensen, K. B. (2008). Intermediality. In W. Donsbach (ed.), International encyclopedia of communication. Malden, MA: Blackwell.

Lash, S. \& Urry, J. (1987). The end of organized capitalism. Cambridge: Polity Press.

Ling, R. \& Lai, C.-H. (2016). Microcoordination 2.0: Social coordination in the age of smartphones and messaging apps. Journal of Communication, August. doi: https://doi.org/10.1111/jcom.12251

Lull, J. (1980). The social uses of television. Human Communication Research, 6(3): 197-209. https://doi. org/10.1111/j.1468-2958.1980.tb00140.x

Marcus, G. E. (1995). Ethnography in/of the world system: The emergence of multi-sited ethnography. Annual Review of Anthropology, 24 (1): 95-117.

Markham, A. N. (1998). Life online: Researching real experience in virtual space. Walnut Creek, CA. Altamira Press.

Markham, T. \& Couldry, N. (2007). Tracking the reflexivity of the (dis)engaged citizen: Some methodological reflections. Qualitative Inquiry, 13(5): 675-695. https://doi.org/10.1177/1077800407301182

Marwick, A. E. \& boyd, D. (2014). Networked privacy: How teenagers negotiate context in social media. New Media \& Society, 16(7): 1051-1067. doi: https://doi.org/10.1177/1461444814543995

Miller, D., Costa, E., Haynes, N., McDonald, T., Nicolescu, R., Sinanan, J., Spyer, J., Venkatraman, S. \& Wang, X. (2016). How the world changed social media. Why we post. London: UCL Press. Retrieved from http://www.oapen.org/download?type=document\&docid=604151

Miller, D. \& Slater, D. (2000). The Internet: An ethnographic approach. Oxford: Berg.

Morse, J. M. \& Niehaus, L. (2016). Mixed method design: Principles and procedures. Milton, Abingdon, UK: Taylor and Francis. Retrieved from http://ebookcentral.proquest.com/lib/kbdk/detail. action? docID $=4586791$

Noy, C. (2008). Sampling knowledge: The hermeneutics of snowball sampling in qualitative research. International Journal of Social Research Methodology, 11(4): 327-344. https://doi. org/10.1080/13645570701401305

Patton, M. Q. (2015). Qualitative research \& evaluation methods: Integrating theory and practice (4th ed.). Thousand Oaks, CA: SAGE Publications, Inc.

Poels, K., Ijsselsteijn, W. A. \& de Kort, Y. (2015). World of Warcraft, the aftermath: How game elements transfer into perceptions, associations and (day)dreams in the everyday life of massively multiplayer online role-playing game players. New Media \& Society, 17(7): 1137-1153. https://doi. org/10.1177/1461444814521596

Radway, J. A. (1984). Reading the romance: Women, patriarchy, and popular literature. Chapel Hill, US: The University of North Carolina Press. Retrieved from http://site.ebrary.com/lib/alltitles/docDetail. action?docID $=10355395$

Silverstone, R. (2006). Domesticating domestication: Reflections on the life of a concept. In T. Berker, Hartmann, M., Punie, Y. \& Ward, K. J. (eds.), Domestication of media and technology (pp. 229-248). Maidenhead, UK: Open University Press. Retrieved from http://mcgraw-hill.co.uk/openup 
Silverstone, R., Hirsch, E. \& Morley, D. (1994). Information and communication technologies and the moral economy of the household. In R. Silverstone \& E. Hirsch (eds.), Consuming technologies, media and information in domestic spaces. London: Routledge.

Simon, J. \& Ess, C. (2015). The ONLIFE initiative-A concept reengineering exercise. Philosophy \& Technology, 28(1): 157-162. doi: https://doi.org/10.1007/s13347-015-0189-8.

Slater, D. (2002). Social relationships and identity online and offline. In L. Lievrouw \& S. Livingstone (eds.), Handbook of new media: Social shaping and consequences of ICTs (pp. 533-546). London, UK: Sage Publications. Retrieved from http://www.sagepub.co.uk

Thorhauge, A. M. \& Lomborg, S. (2016). Cross-media communication in context: A mixed-methods approach. MedieKultur: Journal of Media and Communication Research, 32(60): 16. doi: https://doi.org/10.7146/ mediekultur.v32i60.22090

Turkle, S. (1995). Life on the screen: Identity in the age of the Internet. 1. Touchstone ed. New York, NY: Touchstone.

Zimmerman, D. H. \& Wieder, D. L. (1977). The diary: Diary-interview method. Urban Life, 5(4): 479-498. https://doi.org/10.1177/089124167700500406. 